\title{
Eating disorders and associated risk factors among Imam Abdulrahman bin Faisal university preparatory year female students in Kingdom of Saudi Arabia
}

Aisha M. Alwosaifer, MD, SBFM, Salwa A. Alawadh, MD, SBFM, Moataza M. Abdel Wahab, PhD, MBChB, Leila A. Boubshait, ABFM, MD, Bader A. Almutairi, MD, SBFM.

\begin{abstract}
الأهداف : تقدير مدى انتشار الإضطرابات الغذائية بين طالبات السنة

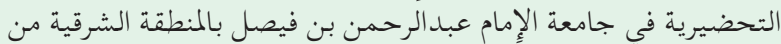

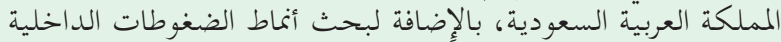

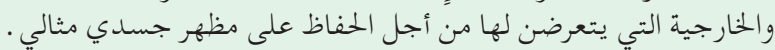

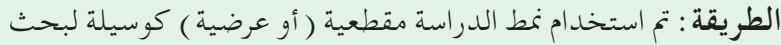

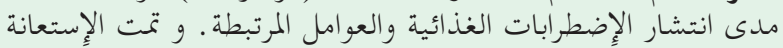

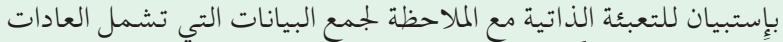

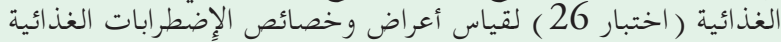

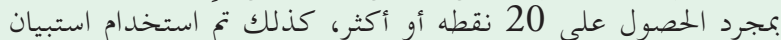

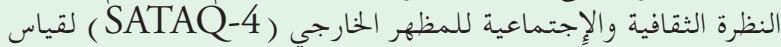

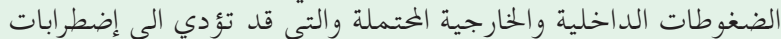

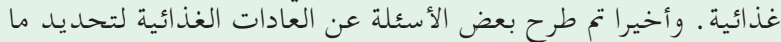

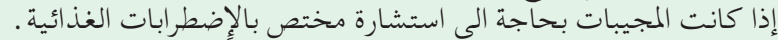

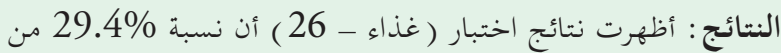
الطالبات تم تصنيفهن تحت

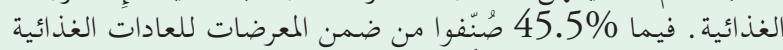
غير الصحية . و أخيرا ما نسبَته

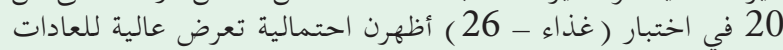

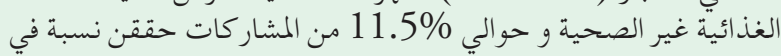

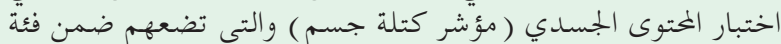

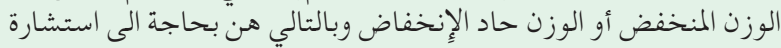

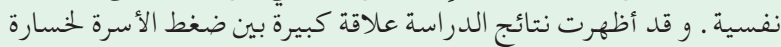

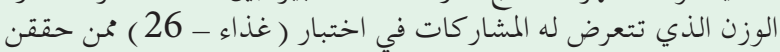

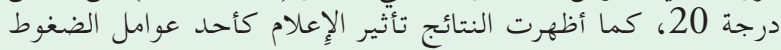

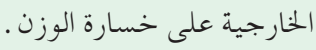

الحخائمة : الإكتشاف المبكر للإضطرابات الغذائية أو العادات الغذائية غير

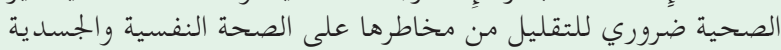

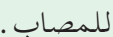

Objectives: To estimate the prevalence of eating disorders among Imam Abdulrahman bin Faisal University (IAU) in Dammam, Kingdom of Saudi Arabia, female students and to investigate the associated factors.
Methods: A cross-sectional study was conducted at IAU, Dammam, Kingdom of Saudi Arabia, in 2016 with 670 participants. Data was collected by selfadministered questionnaires, including the Eating attitude test 26 (EAT-26) and the sociocultural attitudes toward appearance questionnaire (SATAQ-4). Eating behavior questions were asked to determine whether the respondents should seek evaluation for an eating disorder (ED) from a professional.

Results: Eating attitude test 26 results showed that $29.4 \%$ of participants were categorized at a high level of concern for an ED, and $45.5 \%$ were categorized as at risk of having problematic feeding behaviors. Of the participants who scored above 20 on the EAT26, $60.7 \%$ demonstrated high-risk feeding behavior attitudes, and approximately $11.5 \%$ who scored a body mass index (BMI) classified as underweight or very underweight required referral to a psychologist. A significant relationship was found between family stress to lose weight and EAT-26 scores above 20. The media was also found to represent external influence to lose weight.

Conclusion: This study concluded that early detection of EDs or problematic feeding behaviors and attitude is vital to minimize the risks to physical health and well-being of the sufferers' experiences.

Saudi Med J 2018; Vol. 39 (9): 910-921 doi: 10.15537/smj.2018.9.23314

From the Department of Family Medicine (Alwosaifer, Alawadh, ALmutairi), King Fahad Military Medical Complex, from the Department of Family Medicine (Abdel Wahab, Boubshait), Imam Abdulrahman bin Faisal University, Dammam, Kingdom of Saudi Arabia, and from the Department of Biostatistics (Abdel Wahab), High Institute of Public Health, Alexandria University, Alexandria, Eygpt.

Received 10th June 2018. Accepted 10th July 2018.

Address correspondence and reprint request to: Dr. Aisha M. Alwosaifer, Department of Family Medicine, King Fahad Military Medical Complex, Dammam, Kingdom of Saudi Arabia. E-mail: draisha. mohanna@gmail.com

ORCID ID: orcid.org/0000-0002-5927-2161 
$\mathrm{E}^{\mathrm{a}}$ ating disorders (EDs) feature disturbances which impair health and psychosocial functioning. ${ }^{1}$ With health risks ranging from low blood pressure, slow heart rate and severe dehydration in anorexia. ${ }^{1}$ And electrolyte and type 2 diabetes mellitus in bulimia to death. ${ }^{1}$

Both males and females experience EDs during adolescence and young adulthood. ${ }^{1}$ However, rates are higher in young and adult females ${ }^{2,3}$ Which can begin as young as 6 and continue into adulthood. ${ }^{3}$

The American Psychiatric Association's Diagnostic and Statistical Manual of Mental Disorders, 5th Edition (DSM-5) categorizes EDs into mutually exclusive categories based on observed symptoms (Appendix 1), with young adult females particularly at high risk. ${ }^{2}$

Western countries report rates of $0.3 \%$ for anorexia nervosa and $1 \%$ for bulimia among young females. ${ }^{4}$ Studies in Kingdom of Saudi Arabia, ${ }^{5}$ Arab countries, ${ }^{6,7,8}$ and in an international context,,${ }^{9,10}$ report rates for young adult females of $24 \%,{ }^{11,12,13}$ in which the usual presentation is with a mental health problem including anxiety, depression, or a behavioral disorder. ${ }^{11}$ Eastern countries report that subclinical types of EDs are more prevalent. ${ }^{14,15}$

Studies of EDs and the associated risk factors largely focus on sociocultural factors, perceived body image, the media, and perceived pressure from family and peers, individual comparisons of one's body with others, perceived pressure from peers and family members, media representations and sociocultural influences. ${ }^{16,17,18,19}$

Early recognition of mild forms of ED can help prevent inappropriate eating behaviors and attitudes leading to more severe forms of ED. ${ }^{2,20}$ Eating disorder prevalence rates and associated risk factors among women (and men) in Kingdom of Saudi Arabia have been particularly understudied. With a focus on young adolescent girls.

As Saudi women comprise $60 \%$ of all college students in the Kingdom of Saudi Arabia. ${ }^{21}$ This study aims to estimate the prevalence of EDs among orientationyear female students in Imam Abdulrahman bin Faisal University, Dammam, Kingdom of Saudi Arabia, and to determine the association between EDs and internal and external pressure affecting these females.

Methods. This study was performed with a crosssectional study design conducted at Imam Abdulrahman

Disclosure. Authors have no conflict of interests, and the work was not supported or funded by any drug company. bin Faisal University, Dammam, Kingdom of Saudi Arabia, academic year 2015-2016. This is the largest government university in the Eastern Region of the Kingdom of Saudi Arabia; students join a preparatory year of 8 tracks (health, design, literature, etc.) and then, according to their grades, join different colleges the following year.

A stratified, random sampling technique was used to recruit preparatory-year female students from 4 specialty colleges at Imam Abdulrahman bin Faisal University in Dammam, Kingdom of Saudi Arabia, namely, medicine, interior design, science and community college, using proportional allocation. Excluding non-Saudi and pregnant females. A sample size of 670 participants were included in this study, which exceeded the minimum required sample size 480, calculated using Epi Info 3.4, assuming $50 \%$ prevalence of EDs, at a $95 \%$ confidence level and precision of 5 and further expecting an $80 \%$ response rate.

Data collection was carried out using both a pre-scheduled questionnaire (Appendixes 1) and anthropometric measurements. All data were collected by the primary investigators with the assistance of 3 trained nurses.

The questionnaire comprised 3 main sections. The first section collected participants' socio-demographic data. Part of this section was adopted from the original EAT-26 questionnaire developed by Garner and Garfinkel in 1979, and additional variables were included in the questionnaire by the researchers after thorough literature review and given the association identified in many studies between higher socioeconomic status and more extreme eating attitudes and behaviors. ${ }^{22}$

The second section measured abnormal eating and weight concerns, using the 26 items of the EAT-26 questionnaire. Each item was answered on a 6-point Likert scale, giving a possible range of 0-78. An additional 5 eating behavior questions were included in the questionnaire (Appendix 2).

The third section of the data collection instrument comprised the socio-cultural attitudes toward appearance questionnaire (SATAQ-4), a 22-item questionnaire, each question measured on a 5-point Likert scale. This supported the collection of data related to the potential external pressure on the individual that might lead to an increase or decrease in the prevalence of EDs. The SATAQ-4 focused on 4 sociocultural domains: self-pressure to be thin or muscular; family pressure (including parents, brothers, sisters, relatives) toward appearance; peer pressure (including close friends, classmates, and other social contacts) toward appearance; and media pressures (including television, 
magazines, the internet, movies, billboards, and advertisements) toward appearance (Appendix 3). The questionnaire achieved a Cronbach alpha score $>0.8$ for the 3 sections.

The questionnaire was originally developed in English and then double translated from English into Arabic then to English by 2 certified translators.

Table 1 - Distribution of study participants according to sociodemographic characteristics.

\begin{tabular}{|c|c|}
\hline Characteristic $(\mathrm{N}=656)$ & n (\%) \\
\hline \multicolumn{2}{|l|}{ Marital status } \\
\hline $\begin{array}{l}\text { Single } \\
\text { Married } \\
\text { Divorced } \\
\text { Widowed }\end{array}$ & $\begin{array}{c}595(90.7) \\
57(8.7) \\
3(0.5) \\
1(0.2)\end{array}$ \\
\hline \multicolumn{2}{|l|}{ Order in family } \\
\hline $\begin{array}{l}\text { Oldest } \\
\text { Middle } \\
\text { Youngest } \\
\text { Only child }\end{array}$ & $\begin{array}{c}141(21.6) \\
410(62.7) \\
101(16.4) \\
2(0.3)\end{array}$ \\
\hline \multicolumn{2}{|l|}{ Living with } \\
\hline $\begin{array}{l}\text { Parents } \\
\text { Husband } \\
\text { Alone } \\
\text { Other }\end{array}$ & $\begin{array}{l}63(93.4) \\
34(5.2) \\
4(0.06) \\
5(0.08)\end{array}$ \\
\hline \multicolumn{2}{|c|}{ Standard achievment admission test } \\
\hline $\begin{array}{l}90-100 \% \\
89-70 \% \\
<70 \%\end{array}$ & $\begin{array}{c}112(17.1) \\
503(76.7) \\
41(6.2)\end{array}$ \\
\hline \multicolumn{2}{|l|}{ General abilities (skills) } \\
\hline $\begin{array}{l}90-100 \% \\
89-70 \% \\
<70 \%\end{array}$ & $\begin{array}{c}173(26.4) \\
464(70.8) \\
18(2.7)\end{array}$ \\
\hline \multicolumn{2}{|l|}{ High school GPA } \\
\hline $\begin{array}{l}90 \%-100 \% \\
70 \%-89 \% \\
<70 \%\end{array}$ & $\begin{array}{c}633(96.5) \\
23(3.5) \\
0(0.0)\end{array}$ \\
\hline \multicolumn{2}{|c|}{ Family monthly income (SR) } \\
\hline $\begin{array}{l}<5000 \\
5000-10000 \\
10001-15000 \\
>15000\end{array}$ & $\begin{array}{c}28(4.3) \\
123(19.0) \\
177(27.4) \\
319(49.3)\end{array}$ \\
\hline \multicolumn{2}{|l|}{ Father Education } \\
\hline $\begin{array}{l}\text { Illiterate } \\
\text { Primary } \\
\text { Middle } \\
\text { Secondary } \\
\text { University } \\
\text { Postgrad } \\
\text { Institute }\end{array}$ & $\begin{array}{c}7(1.1) \\
25(3.8) \\
67(10.2) \\
163(24.8) \\
350(53.4) \\
33(5.0) \\
11(1.7)\end{array}$ \\
\hline \multicolumn{2}{|l|}{ Mother Education } \\
\hline $\begin{array}{l}\text { Illiterate } \\
\text { Primary } \\
\text { Middle } \\
\text { Secondary } \\
\text { University } \\
\text { Postgrad } \\
\text { Institute }\end{array}$ & $\begin{array}{c}19(2.9) \\
66(10.1) \\
84(12.8) \\
175(26.7) \\
277(42.2) \\
6(0.9) \\
29(4.4)\end{array}$ \\
\hline
\end{tabular}

Classes were selected by simple random sampling. All students in the selected classes were invited to participate; Students whom did not want to participate in the study were given permission to leave the classroom. Yet, the response rate was $98 \%$. Participants were given 15 minutes at the end of the class lectures to complete the questionnaire. Two anthropometric measures were taken by a trained nurse in a one-to-one setting to ensure participants' privacy: height $(\mathrm{m})$, using a digital telescopic wall-mounted stadiometer; weight $(\mathrm{kg})$, using an electronic scale.

Fourteen incomplete questionnaires were excluded from the data analysis, resulting in 656 eligible for analysis (colleges of medicine [ $\mathrm{n}=151]$, interior design $[n=61]$, science $[n=319]$, and community college $[n=125])$; the data was entered in SPSS version 20.0 software (IBM Corp., Armonk, NY, USA).

The EAT-26 items formed 3 subscales: dieting, Bulimia/food preoccupation, and oral control. The subscale scores were computed by summing all items assigned to that scale as follows: dieting (13 items); Bulimia and food preoccupation (5 items); oral control (7 items).

Items 1-25 were scored as follows: Always=3, Usually $=2$, Often $=1$; sometimes, rarely and never $=0$; item 26 was scored in the reverse direction. A score of 20 or more on questions 1-26 was deemed to indicate that the participant was at high risk for developing an ED. If a participant checked any of the 5 additional behavior questions or scored 20 or more in EAT-26, she was considered liable for referral to a trained mental health professional for an evaluation.

The SATAQ-4 items formed 5 subscales: Internalization thin/low body fat items 3-5, 8 and 9; Internalization muscular/athletic items $1,2,6,7$, and 10; pressure of family items 11-14; pressure of peers items 15-18; pressure of media items 19-22. Each of the test items was scored on a 5-point variable scale: definitely disagree $=1$; mostly disagree $=2$; neither agree nor disagree $=3$; mostly agree $=4$; and definitely agree $=5$. An average score percent was computed for each of the 5 subscales.

Any behavioral eating questions that yielded a positive answer indicated that the respondent should seek evaluation from a professional.

Body mass index was calculated as body weight (kg) divided by height $\left(\mathrm{m}^{2}\right)$ and then categorized as underweight $(\mathrm{BMI}<18.5)$, normal $(18.5 \leq 25)$, overweight $(25 \leq 30)$, and obese (BMI of 30 or more).

Descriptive statistics were presented as frequency and percent and summary statistics (median and range). The chi-square test was used to test the association of 


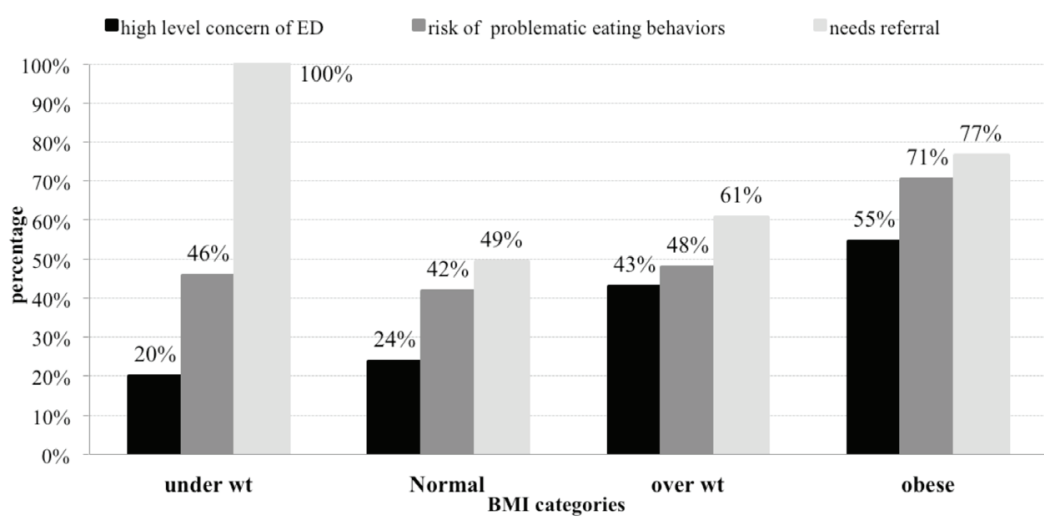

Figure 1 - Distribution of high level of concern of Ed, risk of problematic ED, and need for referral among different BMI categories. BMI - body mass index, ED- Eating disorders

categorical variables with EDs, referral, and BMI categories.

The SATAQ-4, 5 subscales score percent were tested using Shapiro-Wilk test and were found to be not following normal distribution. Relationships between SATAQ-4 items and the presence of eating disorders, referral and BMI categories were tested using MannWhitney $U$ and Kruskal-Wallis tests. A $p$-value $<0.05$ was considered significant.

The local Ethical Committee approved this study, and permission was also sought and obtained from the IAU, Dammam, Kingdom of Saudi Arabia.

Results. The study comprised 656 female students aged 18 - 23 years old, with a mean of $18.7 \pm 0.74$ years; other demographic data are presented in Table 1.

As shown in Table 2, 29.4\% were categorized at a high level of concern for an ED based on EAT-26 scores. Notably, $45.5 \%$ of participants were categorized to be at risk of having problematic eating behaviors. More than half the participants $61.5 \%$ had a BMI within normal range, $19.8 \%$ were overweight, $11.5 \%$ were underweight and $7 \%$ were obese. Their distribution among different specialty colleges was not statistically significant ( $p=0.326, p=0.347$, and $p=0.903$ ).

Participants who scored above 20 on the EAT-26 formed $54.5 \%$ of obese participants $(\mathrm{OR}=3.8$, $95 \% \mathrm{CI}=2.02-7.28)$ versus $43 \%$ of overweight participants $(\mathrm{OR}=2.4, \quad 95 \% \quad \mathrm{CI}=1.56-3.71), \quad 23 \%$ of normal-weight participants [reference group], and $20 \%$ of underweight participants $(\mathrm{OR}=0.8$, $95 \% \quad \mathrm{CI}=0.4-1.5) \quad\left(\mathrm{X}^{2}=32.7, \quad p=0.0001\right)$. High-risk eating attitudes were highest among obese $70 \%$ $(\mathrm{OR}=3.3,95 \% \mathrm{CI}=1.68-6.57)$ followed by overweight
$48 \% \quad(\mathrm{OR}=1.28,95 \% \mathrm{CI}=0.85-1.94)$, underweight $46 \%(\mathrm{OR}=1.17,95 \% \mathrm{CI}=0.7-1.96)$, and then normal weight $42 \%$ [reference group], $\left(\mathrm{X}^{2}=13.5, p=0.003\right)$. For students who needed referral, they were $100 \%$ of underweight, $76.6 \%$ of obese [3.37,1.66-6.8], almost $61 \%$ of overweight $(\mathrm{OR}=1.6,95 \% \mathrm{CI}=1.06-2.38)$, and about half of normal-BMI students [reference group], $\left(\mathrm{X}^{2}=74.2, p=0.0001\right)$ (Figure 1).

Table 3 shows that normal weight was at a higher percent among married students 65\% than single $61.3 \%$, divorced or widowed participants 50\% [2 cases]), $p=0.002$. Moreover, normal weight was higher among those living with their parents $62.5 \%$ than among those living with their husbands $53 \%$, or with another relative $40 \%$ or living alone one case of 4 , $p=0.002$. High level of concern for an ED and need for referral were of higher percent among those whom had lower grades in skills test (general abilities) grades $<90 \%(\mathrm{OR}=1.78,95 \% \mathrm{CI}=1.14-2.77),(\mathrm{OR}=1.65,95 \%$ $\mathrm{CI}=1.16-2.35)$, compared to higher grades $90-100 \%$, $p=0.032, p=0.018$.

Otherwise, no statistically significant associations were found between the studied demographic and socioeconomic characteristics and any high level of concern for an ED, problematic eating behaviors, or the need for referral to a psychologist to address eating behavior issues.

Figures 2 shows that score percentages of participants' internalizations for thin body shape or for a muscular body ranged from $20-100 \%$, with median scores of $75 \%$ and $72 \%$. Higher scores were calculated among those with a high level of concern for an ED compared to participants not to be of concern. A higher median 
Table 2 - Distribution of participants in each specialty college, according to level of concern, BMI, and need for referral.

\begin{tabular}{|c|c|c|c|c|c|c|}
\hline \multirow[t]{2}{*}{ EAT-26 } & \multicolumn{5}{|c|}{ College } & \multirow[t]{2}{*}{$P$-value } \\
\hline & \multicolumn{5}{|c|}{ n (\%) } & \\
\hline High level of concern & $31(23.8)$ & $11(24.4)$ & $98(31.7)$ & $39(31.2)$ & $179(29.4)$ & \multirow{2}{*}{0.326} \\
\hline No concern & $99(76.2)$ & $34(75.6)$ & $211(68.3)$ & $86(68.8)$ & 430 (70.6) & \\
\hline \multicolumn{7}{|l|}{ Eating behavior } \\
\hline Risky & $55(42.3)$ & $26(57.8)$ & $139(45.0)$ & $57(45.6)$ & $277(45.5)$ & \multirow{2}{*}{0.347} \\
\hline No risk & $75(57.7)$ & $19(42.2)$ & $170(55.0)$ & $68(54.4)$ & $332(54.5)$ & \\
\hline \multicolumn{7}{|l|}{$B M I$} \\
\hline Very underweight & $9(6.0)$ & $5(8.2)$ & $21(6.6)$ & $14(11.2)$ & $49(7.5)$ & \multirow{7}{*}{0.903} \\
\hline Underweight & $7(4.6)$ & $2(3.3)$ & $12(3.8)$ & $5(4.0)$ & $26(4.0)$ & \\
\hline Normal & $98(64.9)$ & $33(54.1)$ & $200(62.7)$ & $73(58.4)$ & $404(61.6)$ & \\
\hline Overweight & $30(19.9)$ & $16(26.2)$ & $60(18.8)$ & $24(19.2)$ & $130(19.8)$ & \\
\hline Obese I & $6(4.0)$ & $3(4.9)$ & $16(5.0)$ & $6(4.8)$ & $31(4.7)$ & \\
\hline Obese II & $1(0.7)$ & $1(1.6)$ & $8(2.5)$ & $2(1.6)$ & $12(1.8)$ & \\
\hline Obese III & $0(0.0)$ & $1(1.6)$ & $2(0.6)$ & $1(0.8)$ & $4(0.6)$ & \\
\hline \multicolumn{7}{|l|}{ Referral } \\
\hline Needs referral & $82(54.3)$ & $39(63.9)$ & $197(61.8)$ & $80(64.0)$ & $398(60.7)$ & \multirow{2}{*}{0.146} \\
\hline No referral & $69(45.7)$ & $22(36.1)$ & $122(38.2)$ & $45(36.0)$ & $258(39.3)$ & \\
\hline \multicolumn{7}{|c|}{ EAT-26 - eating attitude test $26, \mathrm{BMI}-$ body mass index } \\
\hline
\end{tabular}

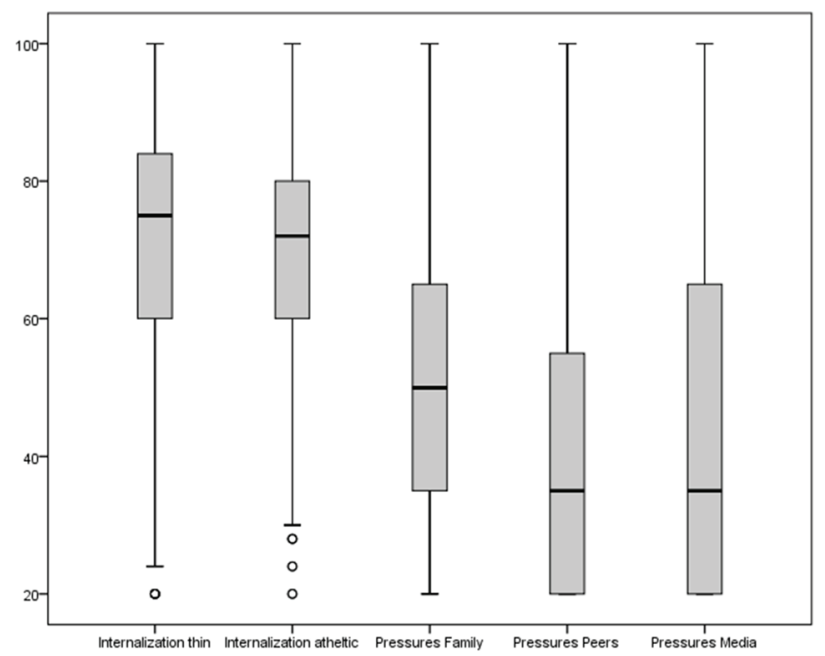

Figure 2 - Internal and external pressures on participants to maintain their ideal body image or to lose weight.

score for internalization of thin body shape was also found in participants at risk for problematic eating behaviors compared to participants not found to be at risk (Figure 3).

Similarly, higher median scores for internalization of thin body shape or of muscular body shape were also found for participants in need of referral compared to those not in need of referral. Internalization of thin body shape and muscular body shape were highest in obese participants, followed by overweight participants, normal participants, and then underweight participants. Median scores are shown in Figure 3. The differences between the BMI and internalization for thin body shape groups was found to be statistically significant ( $p=.0001)$, but not for muscular body shape $(p=0.203)$.

Regarding external pressure from family, the media, and peers to lose weight, the median score percent was higher for family pressure $50 \%$, followed by the media $35 \%$, and peers $35 \%$.

The external pressure from family, media, and peers had higher scores among those at high level of concern for an ED, at high risk of problematic eating behaviors, and those in need for referral than others with no risk or need of referral. The differences in these scores were statistically significant $(p=0.0001)$. Median score percentages of the SATAQ- 4 data for each group are demonstrated in Figures 2\&3.

Discussion. The main finding in this study is that $29.4 \%$ of preparatory-year Saudi female students studying at the Imam Abdulrahman bin Faisal University in Dammam, Kingdom of Saudi Arabia, were categorized at high level of concern for an ED, having achieved a score of 20 or more on the EAT-26. This prevalence rate is slightly higher than the $24 \%$ reported by Bano, et al. ${ }^{11}$ From a regional perspective, the $28.8 \%$ prevalence rate reported in this study is below the finding reported by Madanat et al, ${ }^{23} 45.2 \%$ 
EDs among female university students ... AlWosaifer et al

Table 3 - Distribution of sociodemographic data of orientation-year students according to level of concern, BMI, and need for referral.

\begin{tabular}{|c|c|c|c|c|c|c|c|}
\hline \multirow[t]{2}{*}{ Characteristic } & \multirow{2}{*}{$\begin{array}{c}\text { EAT-26 } \\
\text { High level of concern } \\
\mathrm{n}(\%)\end{array}$} & \multirow{2}{*}{$\begin{array}{c}\text { Behavioral } \\
\text { risk } \\
\text { n (\%) }\end{array}$} & \multirow{2}{*}{$\begin{array}{c}\text { Referral } \\
\text { Needs referral } \\
\text { n }(\%)\end{array}$} & \multicolumn{4}{|c|}{ BMI } \\
\hline & & & & Under weight & $\begin{array}{l}\text { Normal } \\
\text { n }(\%)\end{array}$ & Over-weight & Obese \\
\hline \multicolumn{8}{|l|}{ Marital status } \\
\hline Single & $163(29.6)$ & $250(45.4)$ & $351(59.0)$ & $60(10.1)$ & $365(61.3)$ & $123(20.7)$ & $47(7.9)$ \\
\hline Married & $15(27.8)$ & $24(44.4)$ & $35(61.4)$ & $13(22.8)$ & $37(64.9)$ & $7(12.3)$ & $-(-)$ \\
\hline Divorced or widow & $2(25.0)$ & $3(75.0)$ & $3(75.0)$ & $2(50.0)$ & $2(50.0)$ & $-(-)$ & $-(-)$ \\
\hline$P$-value & 0.944 & 0.489 & 0.765 & \multicolumn{4}{|c|}{$0.002^{*}$} \\
\hline \multicolumn{8}{|l|}{ Monthly Income (SR) } \\
\hline$<5,000$ & $10(38.5)$ & $15(57.7)$ & $20(71.4)$ & $5(17.9)$ & $14(50.0)$ & $6(21.4)$ & $3(10.7)$ \\
\hline $5,000-10,000$ & $33(27.5)$ & $54(45.0)$ & 77 (62.6) & $19(15.4)$ & $72(58.5)$ & $20(16.3)$ & $12(9.8)$ \\
\hline $10,001-15,000$ & $46(27.5)$ & $76(45.5)$ & $105(59.3)$ & $26(14.7)$ & $101(57.1)$ & $40(22.6)$ & $10(5.6)$ \\
\hline$>15,000$ & $90(30.4)$ & $132(44.6)$ & $185(58.0)$ & $23(7.2)$ & $211(66.1)$ & $63(19.7)$ & $22(6.9)$ \\
\hline$P$-value & 0.646 & 0.644 & 0.489 & \multicolumn{4}{|c|}{0.075} \\
\hline \multicolumn{8}{|l|}{ Living with } \\
\hline Parents & $163(28.7)$ & $261(46.0)$ & $359(58.6)$ & $65(10.6)$ & $383(62.5)$ & $120(19.6)$ & $45(7.3)$ \\
\hline Husband & $11(34.4)$ & $12(37.5)$ & $23(67.6)$ & $10(29.4)$ & $18(52.9)$ & $6(17.6)$ & $0(0.0)$ \\
\hline Alone & $3(75.0)$ & $1(25.0)$ & $3(75.0)$ & $0(0.0)$ & $1(25.0)$ & $3(17.6)$ & $0(0.0)$ \\
\hline Others & $2(40.0)$ & $3(60.0)$ & $4(80.0)$ & $0(0.0)$ & $2(40.0)$ & $1(20.0)$ & $2(40.0)$ \\
\hline$P$-value & 0.146 & 0.587 & 0.567 & \multicolumn{4}{|c|}{$0.002^{*}$} \\
\hline \multicolumn{8}{|l|}{ High school GPA } \\
\hline $90 \%-100 \%$ & $172(29.3)$ & $268(45.7)$ & $373(58.9)$ & 69 (10.9) & $392(61.9)$ & 125 (19.7) & $47(7.4)$ \\
\hline $70 \%-89 \%$ & $7(31.8)$ & $9(40.9)$ & $16(69.6)$ & $6(26.1)$ & $12(52.2)$ & $5(21.7)$ & $0(0.0)$ \\
\hline$P$-value & 0.799 & 0.661 & 0.308 & \multicolumn{4}{|c|}{0.105} \\
\hline \multicolumn{8}{|l|}{ Qudorat (skills) } \\
\hline $90-100 \%$ & 31 (20.9) & $63(42.6)$ & $87(50.3)$ & $14(8.1)$ & $112(64.7)$ & $37(21.4)$ & $10(5.8)$ \\
\hline $89-70 \%$ & $143(32.3)$ & $207(46.7)$ & $291(62.7)$ & $57(12.3)$ & $280(60.3)$ & $92(19.8)$ & $35(7.5)$ \\
\hline$<70 \%$ & $5(27.8)$ & $7(38.9)$ & $11(61.1)$ & $4(22.2)$ & $11(61.1)$ & $1(5.6)$ & $2(11.1)$ \\
\hline$P$-value & $0.032^{*}$ & 0.577 & $0.018^{*}$ & \multicolumn{4}{|c|}{0.240} \\
\hline \multicolumn{8}{|l|}{ Tahsili } \\
\hline $100-90 \%$ & $23(24.7)$ & $42(45.2)$ & $60(53.6)$ & 13 (11.6) & $71(63.4)$ & 22 (19.6) & $6(5.4)$ \\
\hline $89-70 \%$ & $142(29.9)$ & $217(45.7)$ & $303(60.2)$ & $56(11.1)$ & $310(61.6)$ & $99(19.7)$ & $38(7.6)$ \\
\hline$<70 \%$ & $14(34.1)$ & $18(43.9)$ & $26(63.4)$ & $6(14.6)$ & $23(56.1)$ & $9(22.0)$ & $3(7.3)$ \\
\hline$P$-value & 0.478 & 0.974 & 0.369 & \multicolumn{4}{|c|}{0.966} \\
\hline \multicolumn{8}{|l|}{ Order in family } \\
\hline Oldest & 47 (34.6) & $55(40.4)$ & $89(63.1)$ & $18(12.8)$ & $77(54.6)$ & $37(26.2)$ & $9(6.4)$ \\
\hline Middle & $108(28.7)$ & $178(47.3)$ & $242(59.0)$ & $49(12.0)$ & $265(64.6)$ & $71(17.3)$ & $25(6.1)$ \\
\hline Youngest & $24(25.3)$ & $43(45.3)$ & $57(56.4)$ & $8(7.9)$ & $59(58.4)$ & $22(21.8)$ & $12(11.9)$ \\
\hline Only child & $0(0.0)$ & $1(50.0)$ & $1(50.0)$ & $0(0.0)$ & $1(50.0)$ & $0(0.0)$ & $1(50.0)$ \\
\hline$P$-value & 0.360 & 0.579 & 0.695 & \multicolumn{4}{|c|}{0.054} \\
\hline Fathers' education & & & & & & & \\
\hline Illiterate & $2(33.3)$ & $3(50.0)$ & $4(57.1)$ & $0(0.0)$ & $3(42.9)$ & $2(28.6)$ & $2(28.6$ \\
\hline $1^{\mathrm{ry}}$ or middle school & $24(28.2)$ & $39(45.9)$ & $60(65.2)$ & $16(17.4)$ & $55(59.8)$ & $13(14.1)$ & $8(8.7)$ \\
\hline 2ry or institute & $54(32.5)$ & $77(46.4)$ & $109(62.6)$ & $20(11.5)$ & $105(60.3)$ & $38(21.8)$ & $11(6.3)$ \\
\hline University or postgraduate & $99(28.1)$ & $158(44.9)$ & $216(56.4)$ & $39(10.2)$ & $241(62.9)$ & $77(20.1)$ & $26(6.8)$ \\
\hline$P$-value & 0.763 & 0.984 & 0.322 & & 0.216 & & \\
\hline Mothers' education & & & & & & & \\
\hline Illiterate & $3(16.7)$ & $8(44.4)$ & $10(52.6)$ & $2(10.5)$ & $13(68.4)$ & $2(10.5)$ & $2(10.5)$ \\
\hline $1^{\mathrm{ry}}$ or middle school & $53(37.1)$ & $74(51.7)$ & $100(66.7)$ & $20(13.3)$ & $88(58.7)$ & $28(18.7)$ & $14(9.3)$ \\
\hline 2ry or institute & $48(24.6)$ & $81(41.5)$ & $121(59.3)$ & $23(11.3)$ & $129(63.2)$ & $40(19.6)$ & $12(5.9)$ \\
\hline University or postgraduate & $75(29.6)$ & $114(45.1)$ & $158(55.8)$ & $30(10.6)$ & $174(61.5)$ & $60(21.2)$ & $19(6.7)$ \\
\hline$P$-value & 0.055 & 0.319 & 0.162 & & 0.902 & & \\
\hline & T-26 - eating attit & t26, BMI - b & nass index, ${ }^{*}$ sta & cally significa & -value $<0.05$ & & \\
\hline
\end{tabular}



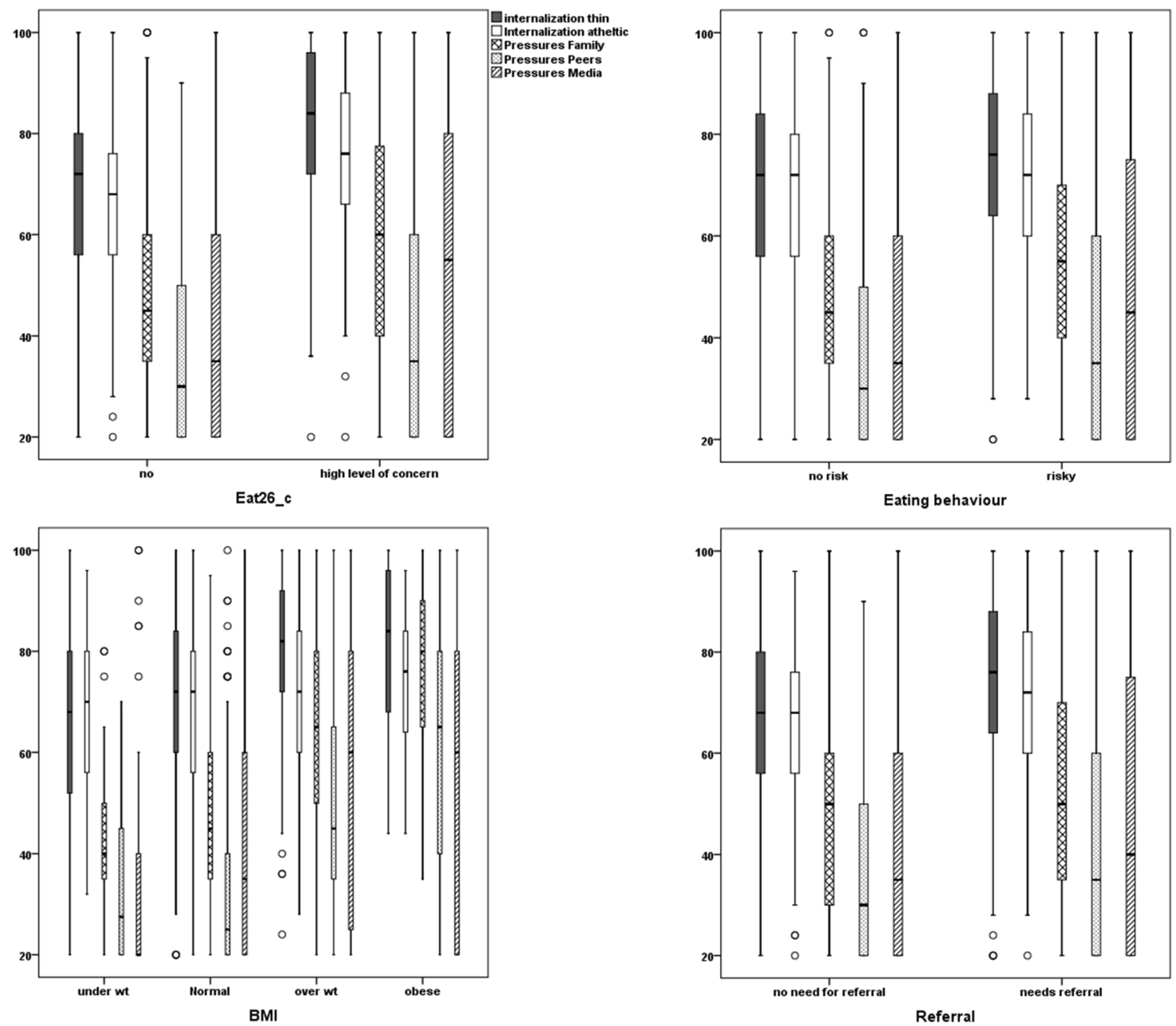

Figure 3 - Relation between SATAQ-4 and high level of concern, BMI and need for referral. BMI - body mass index, SATAQ-4 - socio-cultural attitudes toward appearance questionnaire

of female college students in Jordan required screening for EDs but above the finding by Schulte et al, ${ }^{7} 20 \%$ prevalence rate among female students studying at 2 other universities in Abudabi and Sharga in the United Arab Emirates.

Explaining the differences in ED prevalence rates among young women living in the Kingdom of Saudi Arabia or the Middle East is broadly more difficult due to the lack of research studies of the epidemiology of EDs in the region. From a cultural perspective, Miller et $\mathrm{al}^{24}$ claims that $\mathrm{ED}$ prevalence rates will naturally vary across different races and ethnicities and change over time due to the evolution of national culture. This claim is supported in the findings of a systematic review conducted by Keel et $\mathrm{al}^{5}$ that "weight concerns may be a culturally bound phenomenon, restricted to socio- historical contexts that idealize thinness and denigrate fatness."

The findings in this study highlight that EDs are not culture-specific. Much has been written in recent decades to dispute the conceptualization that EDs among women are primarily a Western phenomenon. ${ }^{5}$ In fact, Campbell et $\mathrm{al}^{25}$ have suggested, at the very least, "risk of an ED is part genetic and part environmental." It may be concluded that the prevalence rate of EDs among young Saudi women may be linked to unique sociocultural factors and different levels of vulnerability toward EDs the study cohort experiences.

The higher prevalence of concerns for an ED among single adult female university students in this study is similar to the finding by Madanat et $\mathrm{al}^{23}$ that single, college-aged women studying in Jordan were more 
prone to external pressure regarding eating than their married counterparts. Eating disorders are complex phenomena in which eating behavior problems are linked to behavioral, cognitive, and emotional factors. ${ }^{26}$ Within this dynamic, marital status and interpersonal relationships more broadly are identified as contributing factors to maintaining EDs. Martínez-González et al, ${ }^{27}$ claimed that solitary eating can be a strong independent risk factor for developing an ED, and this may explain in part the findings in this study.

Family pressure represented the strongest external pressure to lose weight that Saudi female orientationyear students experienced. The influence of family (and peers) on eating behaviors and body-image dissatisfaction among females and males was also reported by Quiles et $\mathrm{al}^{13}$ in their meta-analysis of studies examining this relationship. This finding highlights the importance of developing a deeper understanding of how family influence within specific cultural contexts act as a moderating effect for the development of an ED. For instance, Zeeni et $\mathrm{al}^{17}$ pointed to the role of social customs and cultural expectations as the pressure from family members exert the person to engage in certain eating behaviors.

The media also represented a significant external pressure to lose weight for Saudi female orientationyear students with EAT-26 scores indicating high level of concern about an ED. A number of studies from different fields of research, including EDs, health psychology, and mass communication, pointed to the role of mass media as a pivotal source of information and reinforcement regarding the nature of the thin beauty ideal, the level of importance it is assigned, and how to achieve it. ${ }^{27}$ One of the key implications of the prominent role of the media is that the globalization of media networks and the increasing prevalence of Western ideals promoted through these media outlets will result in a greater proliferation of the Western ideal body image in countries all around the world. ${ }^{27,28}$ The finding that the media might function as a leading external pressure source on adult Saudi female university students suggests that, similar to parents, the media presents a principal social agent for this cohort. That is, the media is a platform for the transmission of ideas, values, norms, attitudes, and behaviors that socialize and construct the social reality. ${ }^{29}$

Finally, this study found that peers are also a source of external pressure on Saudi adult female university students to lose weight. To explain this finding, the case might be that some cultural contexts can lead young women to be more sensitive to and influenced by comments from peers regarding body image than to some other cultural contexts. This implies that the sociocultural context might influence the level of importance placed on social judgments which, in the context of EDs, can translate into the acceptance of certain eating behaviors.

Limitations. It should be noted that the questionnaire instrument designed and implemented for data collection did not consider different scoring if the participants had a chronic disease, were already diagnosed as having an ED, or were on any medications for mood stabilization. Such conditions among the study participants may influence their eating behaviors and BMI measures.

In conclusion, eating disorders continue to be a problem among populations in most societies around the world. In turn, important implications emerge from the findings in this study of a high rate of concern for EDs among Saudi adult female university students and the potential influence of external sociocultural pressure on them to lose weight. Overall, more than one-third of the female students in this study received scores on the EAT-26 that qualified them to be concerned about having an ED. Almost one-half demonstrated problematic eating behaviors, more than one-half required referral to a psychologist to address eating behavior issues, and approximately one-third had a BMI outside of normal weight. Based on these results, this study recommends that suitable screening tools (namely, EAT-26 and SATAQ-4) be used in the university clinic for early detection of an ED and for timely referral to support intervention and health education programs regarding healthy nutrition addressing students and provided in the media.

Acknowledgment. The authors would like to thank https://www.elsevier.com/en-xm for English language editing.

\section{References}

1. Sammarco A. Women's health issues across the life cycle. Burlington (MA): Jones \& Bartlett Publishers; 2016.

2. Golden NH. Eating disorders in adolescence and their sequelae. Best Pract Res Clin Obstet Gynaecol 2003; 17: 57-73.

3. Smolak L. Body image development in childhood. In: Cash T, Smolak L, editors, Body Image: A Handbook of Science, Practice, and Prevention. 2nd edition. New York (NY): Guilford; 2011.

4. Hoek HW, van Hoeken D. Review of the prevalence and incidence of eating disorders. Int J Eat Disord 2003; 34: 383-396.

5. Keel PK, Klump KL. Are eating disorders culture-bound syndromes? Implications for conceptualizing their etiology. Psychol Bull 2003; 129: 747-769. 
6. Thomas J, Khan S, Abdulrahman AA. Eating attitudes and body image concerns among female university students in the United Arab Emirates. Appetite 2010; 54: 595-598.

7. Schulte SJ, Thomas J. Relationship between eating pathology, body dissatisfaction and depressive symptoms among male and female adolescents in the United Arab Emirates. Eat Behav 2013; 14: 157-160.

8. Eapen V, Mabrouk AA, Bin-Othman S. Disordered eating attitudes and symptomatology among adolescent girls in the United Arab Emirates. Eat Behav 2006; 7: 53-60.

9. Suhail K, Zaib-u-Nisa. Prevalence of eating disorders in Pakistan: relationship with depression and body shape. Eat Weight Disord 2002; 7: 131-138.

10. Pinhas L, Morris A, Crosby RD, Katzman DK. Incidence and age-specific presentation of restrictive eating disorders in children: a Canadian Paediatric Surveillance Program study. Arch Pediatr Adolesc Med 2011; 165: 895-899.

11. Bano R, AlShammari E, Banu S. A study on the prevalence and severity of eating disorders among the young population of Hail City in Saudi Arabia. Global Research Analysis 2013; 2: 169-173.

12. Harris EC, Barraclough B. Excess mortality of mental disorder. Br J Psychiatry 1998; $173: 11-53$.

13. Quiles Marcos Y, Quiles Sebastián MJ, Pamies Aubalat L, Botella Ausina J, Treasure J. Peer and family influence in eating disorders: a meta-analysis. Eur Psychiatry 2013; 28: 199-206.

14. Nishizawa Y, Kida K, Nishizawa K, Hashiba S, Saito K, Mita R. Perception of self-physique and eating behavior of high school students in Japan. Psychiatry Clin Neurosci 2003; 57: 189-196.

15. Jackson T, Chen H. Sociocultural predictors of physical appearance concerns among adolescent girls and young women from China. Sex Roles 2008; 58: 402-411.

16. Garrusi B, Garousi S, Baneshi MR. Body image and body change: predictive factors in an Iranian population. Int J Prev Med 2013; 4: 940-948.

17. Zeeni N, Gharibeh N, Katsounari I. The influence of sociocultural factors on the eating attitudes of Lebanese and Cypriot students: a cross-cultural study. J Hum Nutr Diet 2013; 26: 45-52.
18. Mousa TY, Al-Domi HA, Mashal RH, Jibril MA. Eating disturbances among adolescent schoolgirls in Jordan. Appetite 2010; 54: 196-201.

19. Al-Adawi S, Dorvlo AS, Burke DT, Moosa S, Al-Bahlani S. A survey of anorexia nervosa using the Arabic version of the EAT-26 and "gold standard" interviews among Omani adolescents. Eat Weight Disord 2002; 7: 304-311.

20. Klein DA, Walsh BT. Eating disorders: clinical features and pathophysiology. Physiol Behav 2004; 81: 359-374.

21. World Bank. The status of progress of women in the Middle East and North Africa, Washington (DC): World Bank; 2007.

22. Porth C. Essentials of pathophysiology: Concepts of altered states. 4th ed. Philadelphia (PA): Lippincott, Williams \& Wilkins; 2014.

23. Madanat HN, Lindsay R, Campbell T. Young urban women and the nutrition transition in Jordan. Public Health Nutr 2011; 14: 599-604.

24. Miller MN, Pumariega AJ. Culture and eating disorders: a historical and cross-cultural review. Psychiatry 2001; 64: 93-110.

25. Campbell IC, Mill J, Uher R, Schmidt U. Eating disorders, gene-environment interactions and epigenetics. Neurosci Biobehav Rev 2011; 35: 784-793.

26. Bussolotti D, Fernández-Aranda F, Solano R, Jiménez-Murcia S, Turón V, Vallejo J. Marital status and eating disorders: an analysis of its relevance. J Psychosom Res 2002; 53: 1139-1145.

27. Martínez-González MA, Gual P, Lahortiga F, Alonso Y, de Irala-Estévez J, Cervera S. Parental factors, mass media influences, and the onset of eating disorders in a prospective population-based cohort. Pediatrics 2003; 111: 315-320.

28. Lopez-Guimera G, Levine MP, Sánchez-Carracedo D, Fauquet J. Influence of mass media on body image and eating disordered attitudes and behaviors in females: A review of effects and processes. Media Psychology 2012; 13: 387-416.

29. Long DE. Culture and customs of Saudi Arabia. London (UK): Greenwood Press; 2005.

30. Greene JR. Eating disorders: The ultimate teen guide. London (UK): Rowman and Littlefield; 2014.

31. countrymeters [Internet]. Saudi Arabia Population; 2018 [cited 2018 August 16]. Available from: http://countrymeters. info/en/Saudi_Arabia. 
Appendix 1 - DSM-5 diagnostic criteria for eating disorders.

\begin{tabular}{|l|l|} 
Disease & DSM-5 criteria
\end{tabular}

\section{Anorexia nervosa}

\section{Bulimia Nervosa}

\section{Binge Eating Disorder}

1. Persistent restriction of food intake leading to significant low body weight (in context of what is minimally expected for age. sex, developmental trajectory, and physical health) .

2. Either an inlense fear of gaining weight or of becorning fat, or persistent behavior that interferes with weight gain (even though significantly low waight).

3. Disturbance in the way one's bocty weight or shape is experienced, undue influence of body shape and weight on seltevaluation, or persistent lack of recognition of the seriousness of the current low body weight.

1. Eating large amount of food in a discrete pariod of tims 2. A sense of lack of control over eating during the episode. 3. Recurrent inappropriate compensatory behavior in order to prevent weight gain. Like, serf-induced vomiting, misuse of laxatives, diuretics, or other medications, fasting, or excessive exercise.

4. Both occur, on average, at least once a week for three months.

5. Sell-evaluation is unduly influenced by body shape and weight.

6. The disturbance does not occur exclusively during episodes of Anorexia Nervose.

1. Eating large amount of food in a discrete period of time . 2. A sense of lack of control over eating during the episode.

3. eating much more rapidly than normal

4. eating until feeling uncomfortably full

5. eating large amounts of food when not feeling physically hungry

6. eating alone because of feeling embarrassed by how much one is cating

7. Disgusted feeling with oneself, very guilty and depressed.

8. at least once a week for three months 
Appendix 2 - $\quad$ EAT-26 Questionnaire (English).

Eating Attitudes Test (EAT-26) ${ }^{\odot}$

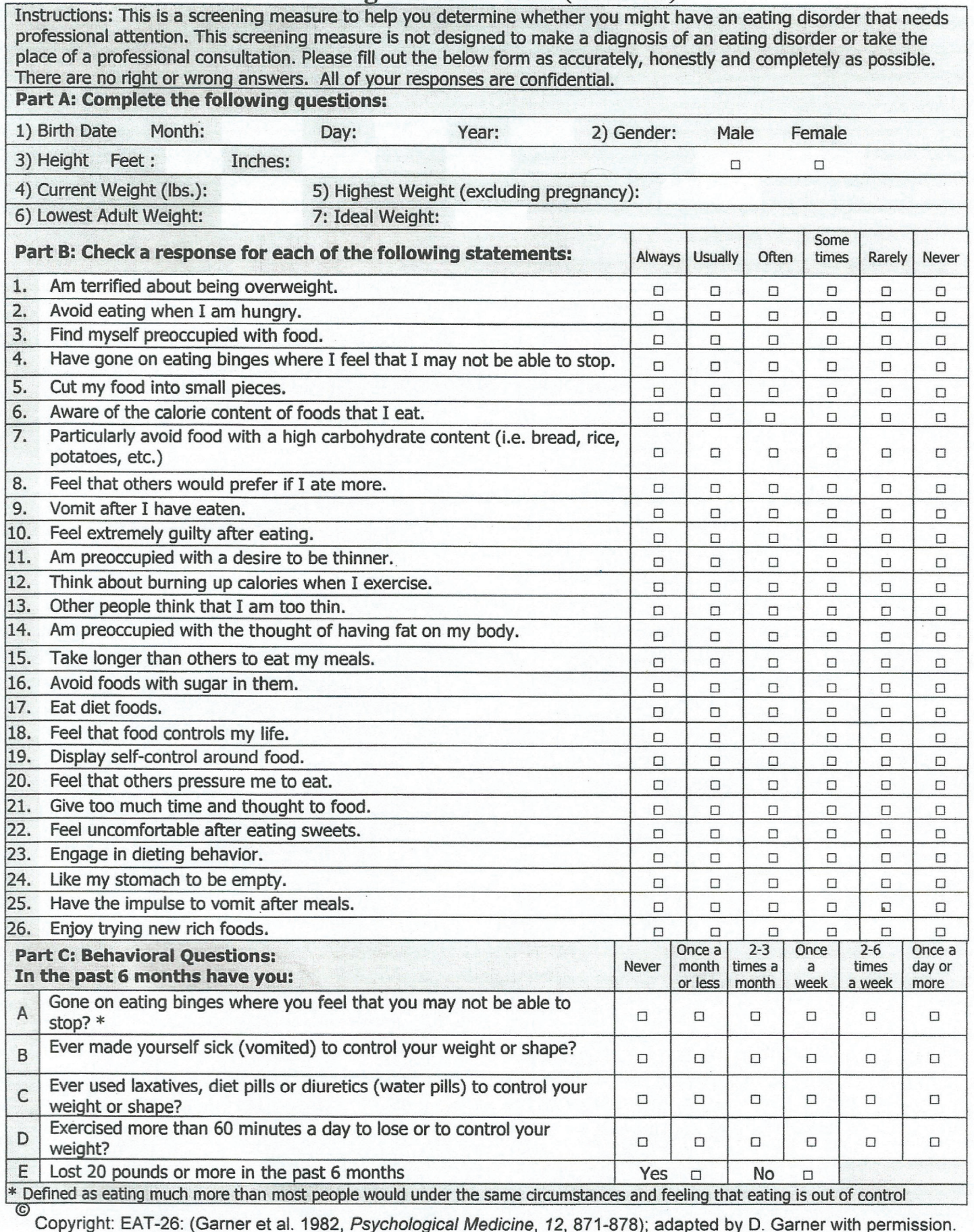


Appendix 3 - $\quad$ SATAQ-4 Questionnaire (English).

Sociocultural Amitudes Towards Appearance Questionnaire- 4

Directioes: Please read each of the following items carefully and indicate the number that best reflects your agreement with the statement.

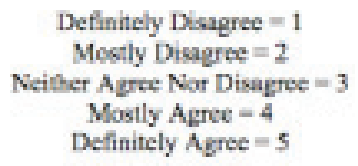

1. It is impoetant foe me to look sthletic.

2. I think a lot about looking mascular.

3. 1 want my body to look very thin.

4. I want my body to look like it has little fat.

5. 1 think a lot about looking thin.

6. 1 spend a lot of time doing things to look more athletic.

7. I think a lot about looking athletic.

8. I want my body to look very lean.

9. I think a lot about having very little body fat.

10. I spend a lot of time doing things to look

\section{Deflnitely \\ Disagree}

Deflnitely Agret 5

Answer the following questioes with relevance to your Family (include; parents, brothers, sisters, selativei):

11. I feel pressure from family members to look thinser.

12. I feel pressure from family members to improve my appearance.

13. Fxmily membes encourage me to decrease my kvel of body fac.

14. Fxmily members encorrage me to get in better shape.

$\begin{array}{lllll}1 & 2 & 3 & 4 & 5 \\ 1 & 2 & 3 & 4 & 5 \\ 1 & 2 & 3 & 4 & 5 \\ 1 & 2 & 3 & 4 & 5\end{array}$

Answer the following questioes with relevance to your Poers (ixclude: close friends, elassmates, other social contacts):

15. My peers enoourge me to get thinner.

16. 1 feel pressure from am peers to improve my uppearince.

17. 1 fecl pecasure frum my poers to look in better shape.

18. I zet pressure fron my peers to decrease my level of body fat.

Answer the following questicas with relevance to the Media (include: veleviaion, magarines, the imemet, movies, billboands, and advertisements):

19. 1 fed preakse frum the media bo look in beller stape

20. 1 fecl prewere frum the media to look thineer.

21. 1 feel peessure from the media is improve iny appearance.

22. 1 feel peessure from the media so decrease my level of body fat. 